\title{
Structural state of plagioclase from the Kobe CK chondrite: Implications for the thermal history of the CK parent body
}

\author{
Yoshihiro NAKAMUTA ${ }^{*}$, Tomoki NAKAMURA ${ }^{* *}$ and Noboru NAKAMURA ${ }^{* * *}$ \\ *Kyushu University Museum, Kyushu University, Hakozaki, Higashi-ku, Fukuoka 812-8581, Japan \\ ** Department of Earth and Planetary Sciences, Faculty of Science, Kyushu University, \\ Hakozaki, Higashi-ku, Fukuoka 812-8581, Japan \\ *** Department of Earth and Planetary Sciences, Faculty of Science, and Graduate School of \\ Science and Technology, Kobe University, Nada, Kobe 657-8501, Japan
}

\begin{abstract}
We determined the structural state of six plagioclase crystals from the Kobe meteorite by measuring the separation between the $1 \overline{3} 1$ and $131 \mathrm{X}$-ray diffraction peaks $(\Delta 131$ parameter) using a Gandolfi camera. The formation temperature of each plagioclase crystal was then estimated by plotting the $\Delta 131$ parameter on the relation diagram between the $\Delta 131$ parameters and temperatures of plagioclase synthesis, as proposed by Smith (1972). Three of the crystals record temperatures of just under $700^{\circ} \mathrm{C}$, while the other three crystals record much lower temperatures. The temperature estimates can be regarded as representing the crystallization temperature of plagioclase, and the highest recorded temperature is thought to correspond to the peak temperature of the thermal metamorphism, close to but not exceeding $700^{\circ} \mathrm{C}$. A thermal model of the CK chondrites is proposed on the assumption that thermal metamorphism, with ${ }^{26} \mathrm{Al}$ decay as a heat source, began prior to accretion of the $\mathrm{CK}$ parent body. The model explains the homogeneous compositions of olivine and pyroxene in CK chondrites, which are inconsistent with the petrographic type suggested by their grain sizes, and explains the occurrence of silicate darkening in almost all CK chondrites.
\end{abstract}

Keywords: CK chondrites, Plagioclase, Structural states, Thermal metamorphism, Metamorphic temperature, Silicate darkening, Planetesimals, Gandolfi camera

\section{INTRODUCTION}

The Kobe meteorite fell on 26 September 1999, in Kobe, Japan (Nakamura et al., 2000), and approximately 20 meteorite fragments, totaling $136 \mathrm{~g}$, were recovered. Two large fragments, Kobe C (14.5 g) and Kobe E (3.7 g), were loaned to us by their finder for the purpose of scientific analysis. Petrographic, chemical, and isotopic descriptions of the Kobe meteorite have been published previously by a consortium of laboratories from Japan and the USA (Nakamura, 2002). The meteorite is classified as a metamorphosed Karoonda-type carbonaceous chondrite (CK4) (Tomeoka et al., 2001, 2005). Karoonda-type carbonaceous chondrites (CK chondrites) are unique among carbonaceous chondrites in that they are thermally metamorphosed, and most of them show a darkening of sili-

doi:10.2465/jmps.060106

Y. Nakamuta, nakamuta@museum.kyushu-u.ac.jp Corresponding author

T. Nakamura, tomoki@geo.kyushu-u.ac.jp

N. Nakamura, noboru@kobe-u.ac.jp cate minerals when observed in transmitted light (Kallemeyn et al., 1991). These unique features of CK chondrites have attracted the attention of researchers because they provide information on thermal processes that occurred within the parent bodies of primitive chondrites in the early solar nebula.

Van Schmus and Wood (1967) categorized the degree of metamorphism of ordinary chondrites as a number of petrographic types based on the chemical compositions and textures of constituent minerals. Many researchers used the petrographic criteria proposed by Van Schmus and Wood (1967) to indicate the thermal processes that took place within the parent bodies of ordinary chondrite (McSween et al., 1988). Kallemeyn et al. (1991) applied some of the petrographic criteria used in studies of ordinary chondrite to carbonaceous chondrites, including: 1) homogeneity of olivine composition, 2) mean diameter of plagioclase, 3) presence or absence of primary glass, 4) chondrule delineation, and 5) coarseness of ground mass grains, and suggested that CK chondrites form a metamorphic sequence, as observed in ordinary 
chondrites. Tomeoka et al. (2005) analyzed the Kobe meteorite and found that olivine crystals have homogeneous compositions (standard deviation of Fa content $=0.4$ ), grain sizes of plagioclase typically range from 50 to 150 $\mu \mathrm{m}$, primary glass is absent, chondrules are moderately defined to well-defined, and the grain size of matrix olivine is typically 5-30 $\mu \mathrm{m}$. Based on the latter two criteria, the authors concluded that a CK4 classification is most appropriate for the Kobe meteorite, although the grain size of plagioclase is consistent with a type 6 classification (Kallemeyn et al., 1991). This discrepancy in classification of the Kobe meteorite indicates a much more complex thermal history for $\mathrm{CK}$ chondrites than that for ordinary chondrites and remains a problem to be solved.

Rubin (1992) attributed the darkening of silicates in CK chondrites to the dispersion of numerous tiny $(<0.3-$ $10 \mu \mathrm{m})$ grains of magnetite and pentlandite into the silicate interiors. He concluded that the darkening was caused by the intrusion of opaque minerals into silicate minerals during intense shock, as with ordinary chondrites. Tomeoka et al. (2001) found numerous small spherical vesicles $(<0.1-3 \mu \mathrm{m}$ in diameter) and grains $(<0.1-5 \mu \mathrm{m})$ of magnetite and pentlandite in olivine grains that show a dark appearance in transmitted light and suggested that the inclusion-rich vesicular olivine is the principal cause of the silicate darkening. The authors concluded that the vesicular olivine was produced by shock metamorphism at a relatively mild shock pressure and a high temperature. The shock events indicated by the darkening of silicate minerals may have played an important role in the thermal history of $\mathrm{CK}$ chondrites along with thermal metamorphism. However, the relationship between thermal metamorphism and shock events, in terms of their effect on the CK parent body, are poorly understood; this is especially true of the timing of shock events in relation to thermal metamorphism.

Plagioclase is a subdominant mineral in the Kobe meteorite. The structural state of plagioclase, i.e., the distribution of $\mathrm{Al}$ and $\mathrm{Si}$ in the four symmetrically nonequivalent tetrahedral sites of the framework, is sensitive to the temperature at which the feldspar forms (Tuttle and Bowen, 1950; Smith and Yoder, 1956; Bambauer et al., 1967; Eberhard, 1967; Smith, 1972; Kroll and Ribbe, 1980). Because plagioclase has a much lower impedance to shock compression than olivine (Stöffler et al., 1991), it would be more susceptible to shock events than olivine (Rubin, 1992; Tomeoka et al., 2001). Thus, it is likely that the structural characteristics of plagioclase in the Kobe meteorite will provide important information on the thermal history of the CK parent body. However, the feldspars have yet to be investigated in this way because of difficulties in obtaining precise $\mathrm{X}$-ray diffraction data from the tiny crystals that are typically found in meteorites. This problem can be overcome by using a Gandolfi camera to obtain precise $\mathrm{X}$-ray powder diffraction data for tiny crystals as small as several tens of microns in size (Nakamuta, 1993, 1999; Nakamuta and Motomura, 1999). The aim of the present study is to report on the structural states of plagioclase from the Kobe meteorite and discuss the thermal history of the CK parent body.

\section{STRUCTURAL STATE OF PLAGIOCLASE AS A GEOTHERMOMETER}

Sodic plagioclase that crystallizes at low temperature forms a structure in which $\mathrm{Al}$ is concentrated in one specific site of the four symmetrically nonequivalent tetrahedral sites of the framework, with $\mathrm{Si}$ in the remaining sites. In contrast, sodic plagioclase that crystallizes at high temperatures in excess of $900{ }^{\circ} \mathrm{C}$ has a structure in which $\mathrm{Al}$ is randomly distributed throughout the four tetrahedral sites. Sodic plagioclase that forms at intermediate temperatures takes an intermediate structure (Tuttle and Bowen, 1950; Smith and Yoder, 1956; Bambauer et al., 1967; Kroll and Ribbe, 1980). The distribution of Si and Al in the unit cell of sodic plagioclase contributes to the entropy term of free energy and is therefore related to temperature.

Smith and Yoder (1956) demonstrated that the separation of the $1 \overline{3} 1$ and 131 diffraction peaks, the $\Delta 131$ parameter, is sensitive to changes in the structural state, i.e., the degree of $\mathrm{Al} / \mathrm{Si}$ order in the tetrahedral sites, and that the $\Delta 131$ parameter can be used to estimate the relative structural state of sodic plagioclase if the $\mathrm{Na}$ and $\mathrm{Ca}$ contents are known. MacKenzie (1957) used hydrothermal experiments that involved crystallizing albite from glass to relate the $\Delta 131$ parameter to the temperature at which pure albite has a given structural state. In his experiments, MacKenzie (1957) found that at each synthesis temperature the crystals that formed after several hours are similar to high-temperature albite in terms of lattice parameters and that these crystals changed over time to attain the characteristics of feldspar at the temperature of crystallization. On the basis of partly dry and partly hydrothermal experiments, Eberhard (1967) related the $\Delta 131$ parameter and temperature of synthesis of sodic plagioclase that contains no Or components. The relation diagram proposed by Eberhard (1967) was evaluated and revised by Smith (1972).

Sodic plagioclase in chondritic meteorites contains a component of $\mathrm{K}$ that affects the lattice parameters and subsequently influences the $\Delta 131$ parameter (Bambauer et al., 1967). To determine the degree of $\mathrm{Al} / \mathrm{Si}$ order and the correct crystallization temperature of sodic plagioclase 
via the $\Delta 131$ parameter and the diagram of Smith (1972), it is necessary to correct the observed $\Delta 131$ parameter for the crystallographic influence of $\mathrm{K}$ in the crystal structure. The crystallographic influence of the Or content on the $\Delta$ 131 parameter of sodic plagioclase was summarized by Kroll and Ribbe (1980), who presented graphs to aid in the crystallographic correction of $\Delta 131$ parameters for Or contents in high and low sodic plagioclases. We can now estimate the correct temperature at which sodic plagioclase in chondrites formed by referring to the diagrams of Smith (1972) and Kroll and Ribbe (1980) provided that both $\mathrm{X}$-ray diffraction data and chemical composition data are available. Nakamuta and Motomura (1999) obtained X-ray powder patterns of individual sodic plagioclase crystals of about $50 \mu \mathrm{m}$ in size from type $6 \mathrm{H}, \mathrm{L}$, and LL chondrites using a Gandolfi camera (Gandolfi, 1967) and an electron-probe microanalyzer. The authors thereby estimated the metamorphic temperatures of type 6 ordinary chondrites.

\section{MATERIALS AND EXPERIMENTS}

In this study, we analyze a polished thin section (PTS) prepared from a slice $(\mathrm{P}-7)$ chipped from the Kobe $\mathrm{C}$ fragment. The textures and chemical compositions of constituent minerals of the Kobe meteorite are described in detail by Tomeoka et al. (2005). Consistent with this earlier study, plagioclase in the PTS analyzed in the present study occurs mainly in the matrix as irregularly shaped grains that are typically $50-150 \mu \mathrm{m}$ in size. Chemical compositions of plagioclase grains were obtained using a JEOL JCXA-733 electron-probe microanalyzer (EPMA) in wavelength dispersive mode. Van Schmus and Ribbe (1968) analyzed feldspar in chondrites using an electronprobe microanalyzer operating at $15 \mathrm{kV}$ and $30 \mathrm{nA}$ specimen current and the electron beam focused to $1 \mu \mathrm{m}$. They found that their experimental conditions provided reliable results for crystalline feldspar without diffusion loss of $\mathrm{Na}$, even if the feldspar crystal had suffered shock. We analyzed at $15 \mathrm{kV}$ and $10 \mathrm{nA}$ specimen current with the electron beam focused to $2 \mu \mathrm{m}$. The $\mathrm{X}$-ray intensity from $\mathrm{Na}$ was measured first among nine analyzed elements to avoid diffusion and bombardment loss of $\mathrm{Na}$.

As noted by Tomeoka et al. (2005), plagioclase in the PTS of the present study varies considerably in chemical composition, even within individual grains, and in part contains numerous tiny inclusions (several microns or less in size) of magnetite and pentlandite. Chemically homogeneous and inclusion-free areas $(30-50 \mu \mathrm{m}$ in size) within individual plagioclase grains were removed from the PTS and mounted on glass fibers of $\sim 3 \mu \mathrm{m}$ diameter for $\mathrm{X}$-ray diffraction analysis using a $114 \mathrm{~mm}$ diameter Gandolfi camera (Gandolfi, 1967). A rotating anode $\mathrm{X}$-ray generator with a $\mathrm{Cr}$-anode $0.2 \times 2 \mathrm{~mm}$ finefilament and a $\mathrm{V}$-filter was used as an $\mathrm{X}$-ray source. The $\mathrm{X}$-ray powder diffraction pattern was recorded twodimensionally on an imaging plate (IP) $35 \mathrm{~mm}$ wide and $350 \mathrm{~mm}$ long, and the intensity data on the IP were read at a $50 \times 50 \mu \mathrm{m}$ pixel size with a Fuji-film BAS-2500 IPscanner. Intensities of diffracted $\mathrm{X}$-rays for each Bragg angle were obtained at intervals of $0.025^{\circ}(2 \theta)$ by averaging those along a Laue cone over 300 pixels of the central part of the IP that had the width of approximately 560 pixels.

By applying a profile fitting technique with a pseudo-Voigt type shape function to the $\mathrm{X}$-ray data, the $\Delta$ 131 parameter, i.e., the separation between the $1 \overline{3} 1$ and 131 diffractions, can be determined with an error of less than 0.01 degrees $(2 \theta)$, even when analyzing extremely small plagioclase grains. The $\Delta 131$ parameters measured with $\mathrm{Cr} K \alpha$ radiation were then converted to those of $\mathrm{Cu} K \alpha$ radiation to enable comparison with data in the literature (Smith, 1972; Kroll and Ribbe, 1980) and corrected for the crystallographic influence of the Or content of plagioclase using the correction diagram of Kroll and Ribbe (1980). The temperature of plagioclase crystallization was estimated from the diagram that relates the $\Delta 131$ parameter to the temperature of plagioclase synthesis (Eberhard, 1967; Smith, 1972) by plotting the corrected $\Delta 131$ parameter.

\section{RESULTS}

Backscattered electron images of plagioclase crystals analyzed in this study are shown in Figure 1, in which the areas removed for $\mathrm{X}$-ray analysis $(30-50 \mu \mathrm{m}$ in size) are indicated by arrows. Four crystals (Crystals 1, 3, 4, and 5) occur within the matrix and have irregular shapes, while two (Crystals 2 and 6) occur around barred olivine chondrules. Before removing samples from the PTS, the chemical composition of each sample was analyzed at three points using EPMA; averaged values are shown in Table 1. As the standard deviations are small for all samples, they can be considered to be compositionally homogeneous: compositions fall in the narrow range of $\mathrm{An}_{54.7-63.3}$. Figure 2 shows a histogram of the An mol\% of all plagioclases randomly analyzed in this study. The data extend over a wide range from $\mathrm{An}_{23.4-90.4}$, as reported previously by Tomeoka et al. (2005); however, approximately $70 \%$ of analyses fall in the range $\mathrm{An}_{50-65}$. Accordingly, as the crystals to be analyzed in terms of structural state fall in the range $\mathrm{An}_{54.7-63.3}$, they can be considered to be representative of plagioclase from the Kobe meteorite.

The X-ray powder diffraction patterns obtained 

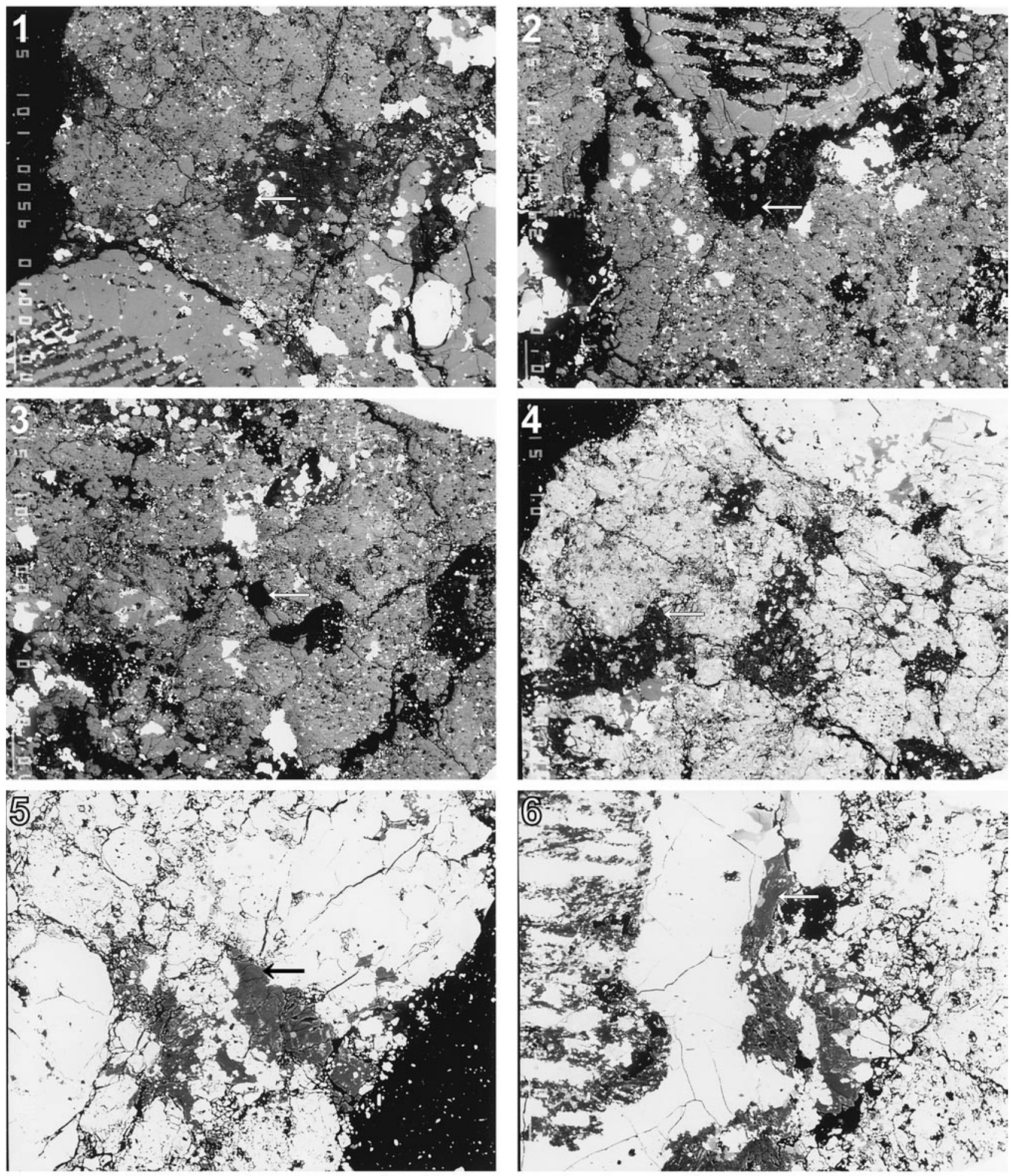

$100 \mu \mathrm{m}$

Figure 1. Backscattered electron images of the six plagioclase crystals analyzed in the present study. The areas removed for X-ray analysis, which are $30-50 \mu \mathrm{m}$ in size, are indicated by arrows.

using the Gandolfi camera are shown in Figure 3. The patterns indicate that all samples are mainly composed of plagioclase. Sharp reflections in the patterns reveal that the plagioclase crystallinity is well and that Bøggild intergrowths, which occur in some plagioclases of bulk compositions $\mathrm{An}_{43-63}$, do not occur in the plagioclase crystals 
Table 1. Chemical compositions of plagioclase crystals subjected to X-ray analysis

\begin{tabular}{|c|c|c|c|c|c|c|}
\hline \multicolumn{7}{|c|}{ Plagioclase crystal } \\
\hline & 1 & 2 & 3 & 4 & 5 & 6 \\
\hline $\mathrm{SiO}_{2}$ & $55.54(20)$ & $52.63(54)$ & $54.15(69)$ & $54.36(95)$ & $53.65(17)$ & $53.57(26)$ \\
\hline $\mathrm{TiO}_{2}$ & $0.00(0)$ & $0.01(1)$ & $0.01(1)$ & $0.02(2)$ & $0.01(2)$ & $0.01(1)$ \\
\hline $\mathrm{Al}_{2} \mathrm{O}_{3}$ & $28.03(13)$ & $28.94(43)$ & $28.82(46)$ & $28.19(99)$ & $28.61(28)$ & $28.85(21)$ \\
\hline $\mathrm{FeO}$ & $0.54(5)$ & $0.58(9)$ & $0.69(5)$ & $0.96(26)$ & $0.57(3)$ & $0.66(3)$ \\
\hline $\mathrm{MnO}$ & $0.02(1)$ & $0.00(0)$ & $0.01(2)$ & $0.02(1)$ & $0.03(3)$ & $0.03(1)$ \\
\hline $\mathrm{MgO}$ & $0.02(1)$ & $0.15(12)$ & $0.11(10)$ & $0.58(77)$ & $0.04(3)$ & $0.04(4)$ \\
\hline $\mathrm{CaO}$ & $10.82(23)$ & $12.87(51)$ & $12.26(50)$ & $11.56(63)$ & $12.00(20)$ & $12.32(34)$ \\
\hline $\mathrm{Na}_{2} \mathrm{O}$ & $4.73(17)$ & $3.96(38)$ & $4.34(29)$ & $4.60(21)$ & $4.13(3)$ & $3.83(26)$ \\
\hline $\mathrm{K}_{2} \mathrm{O}$ & $0.33(1)$ & $0.28(5)$ & $0.33(2)$ & $0.27(3)$ & $0.28(3)$ & $0.23(2)$ \\
\hline Total & 100.03 & 99.42 & 100.72 & 100.56 & 99.32 & 99.54 \\
\hline \multicolumn{7}{|c|}{ Numbers of atoms in 80} \\
\hline $\mathrm{Si}$ & 2.503 & 2.406 & 2.440 & 2.453 & 2.446 & 2.437 \\
\hline $\mathrm{Ti}$ & 0.000 & 0.000 & 0.000 & 0.001 & 0.000 & 0.000 \\
\hline $\mathrm{Al}$ & 1.489 & 1.559 & 1.531 & 1.499 & 1.537 & 1.547 \\
\hline $\mathrm{Fe}$ & 0.021 & 0.022 & 0.026 & 0.037 & 0.022 & 0.025 \\
\hline $\mathrm{Mn}$ & 0.001 & 0.000 & 0.000 & 0.001 & 0.001 & 0.001 \\
\hline $\mathrm{Mg}$ & 0.001 & 0.011 & 0.007 & 0.040 & 0.003 & 0.003 \\
\hline $\mathrm{Ca}$ & 0.522 & 0.630 & 0.592 & 0.558 & 0.586 & 0.601 \\
\hline $\mathrm{Na}$ & 0.413 & 0.351 & 0.379 & 0.402 & 0.365 & 0.337 \\
\hline $\mathrm{K}$ & 0.019 & 0.016 & 0.019 & 0.015 & 0.016 & 0.014 \\
\hline Total & 4.969 & 4.995 & 4.994 & 5.006 & 4.976 & 4.965 \\
\hline An & 54.7 & 63.3 & 59.8 & 57.2 & 60.7 & 63.1 \\
\hline $\mathrm{Ab}$ & 43.3 & 35.1 & 38.3 & 41.2 & 37.7 & 35.5 \\
\hline Or & 2.0 & 1.6 & 1.9 & 1.6 & 1.6 & 1.4 \\
\hline
\end{tabular}

Each plagioclase crystal was analyzed at three points.

Averaged values are shown with standard deviations in parentheses.

analyzed in the present study. Such intergrowths were also absent in the feldspars synthesized by Eberhard (1967). The above result suggests that the relation between the $\Delta 131$ parameter and temperature proposed by Smith (1972) can be applied to the plagioclases studied here, which have compositions of $\mathrm{An}_{57.4-63.3}$. In addition to plagioclase, small amounts of forsterite, magnetite, and diopside were also detected from the $\mathrm{X}$-ray patterns. These minerals are considered to be present within plagioclase crystals as tiny inclusions less than several microns in size.

The $1 \overline{3} 1$ and 131 reflections are usually weak and sometimes overlap with other reflections, as evident in
Figure 3. To obtain precise peak positions and clearly differentiate the two reflections, a profile-fitting technique was applied. An example of the profile-fitting results is shown in Figure 4. Calculated and observed intensities are in good agreement (Fig. 4), indicating that peak positions can be obtained precisely even for weak and overlapping reflections. The standard deviation of peak positions calculated in the process of profile fitting is less than $0.001^{\circ}(2 \theta)$ for all samples.

Table 2 provides a summary of chemical composition data and indices of structural states, i.e., separations between $1 \overline{3} 1$ and 131 reflections in the $\mathrm{Cu} K \alpha$ scale. We plotted the chemical and structural data on the relation 


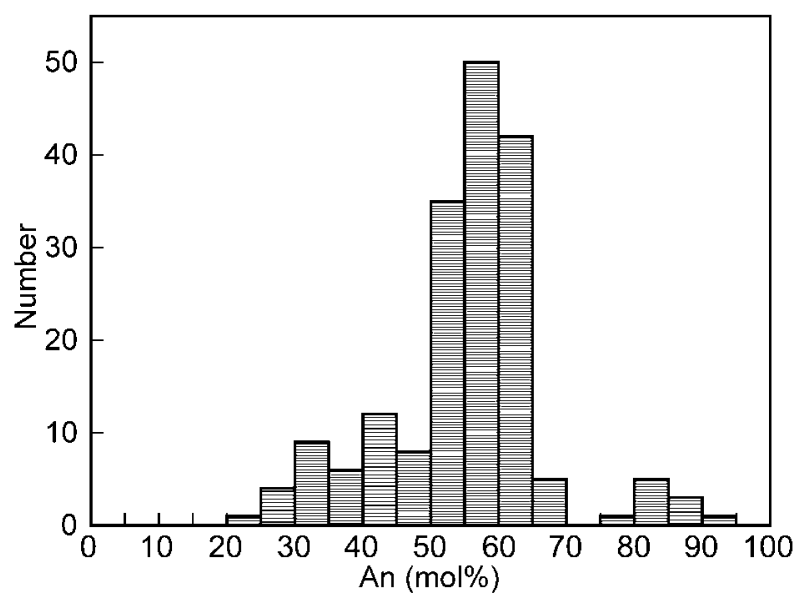

Figure 2. Histogram of the An mol\% of plagioclase crystals.

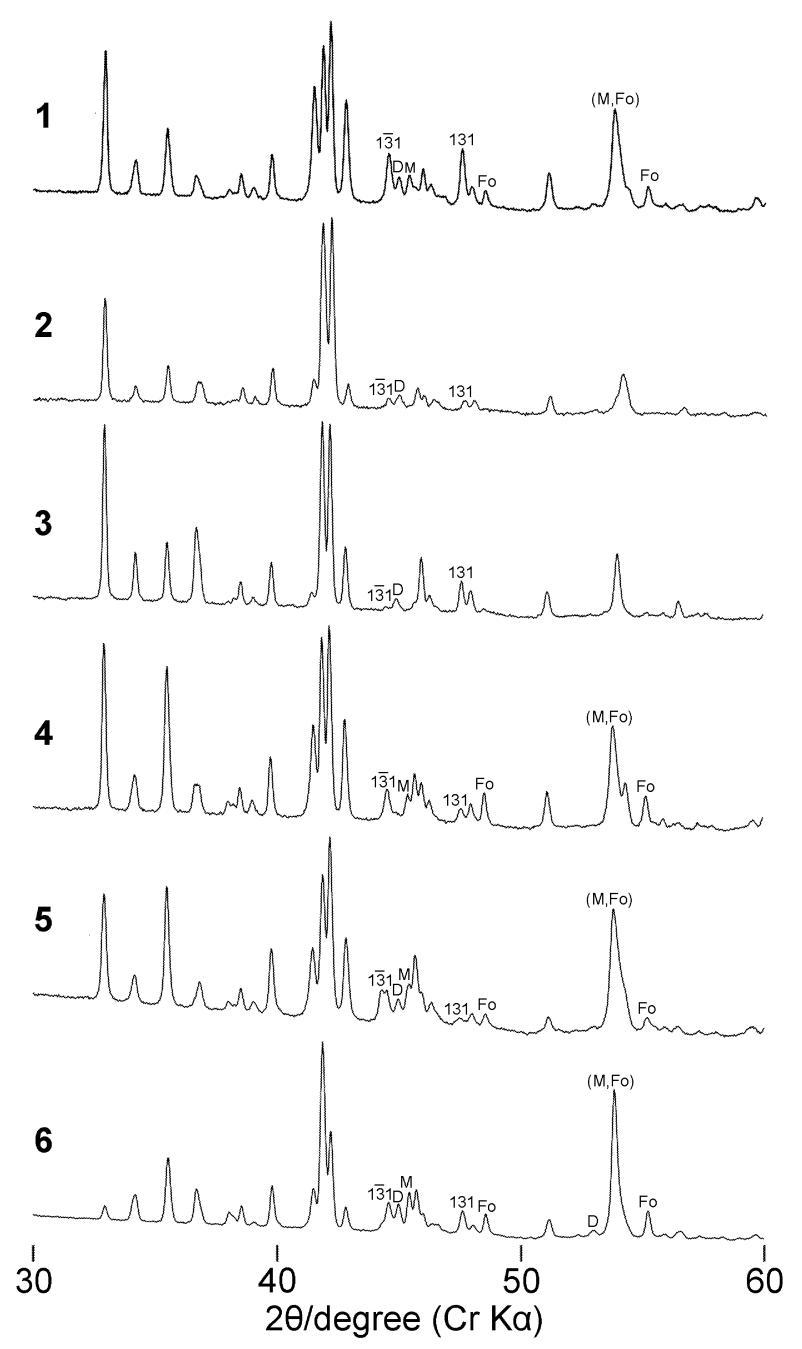

Figure 3. X-ray powder diffraction patterns for the six analyzed plagioclase crystals (30-50 $\mu \mathrm{m}$ in size) obtained using a Gandolfi camera. $1 \overline{3} 1,131: 1 \overline{3} 1$ and 131 reflections of plagioclase, respectively. D, M, Fo: reflections from diopside, magnetite, and forsterite, respectively.

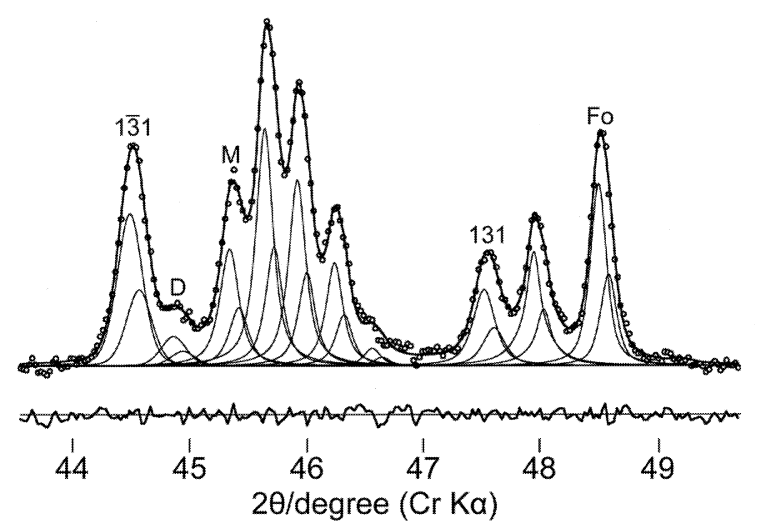

Figure 4. An example of the profile-fitting results. Abbreviations are the same as those in Figure 3. Circles show experimental intensities and the solid thick line is the calculated intensity. Solid thin lines represent the $K \alpha_{1}$ and $K \alpha_{2}$ components of each calculated reflection. Differences between observed and calculated intensities are shown at the bottom of the figure.

diagram between the $\Delta 131$ parameter and the temperature of plagioclase synthesis revised by Smith (1972) (Fig. 5). Smith (1972) drew segments of the 700 and $800{ }^{\circ} \mathrm{C}$ lines as dashed lines because he considered that Eberhard's run table (Eberhard, 1967) did not provide unequivocal evidence. Eberhard drew the trend lines based on synthetic data that he believed to represent equilibrium temperature. Following the work of Eberhard, no further synthetic experiments have been undertaken to determine the equilibrium temperature. Consequently, the temperatures determined in the present study are based on the results of Eberhard (1967).

In Figure 5, three crystals (Crystals 1, 2, and 3) plot immediately below the $700{ }^{\circ} \mathrm{C}$ line, suggesting equivalent temperatures for the three samples at slightly less than $700{ }^{\circ} \mathrm{C}$. The other three crystals plot over a range of lower temperatures. As evident in Figure 5, the potential $\Delta 131$ range for plagioclase of intermediate to $\mathrm{Ca}$-rich compositions is narrower than that for $\mathrm{Na}$-rich plagioclase, and the variation in the $\Delta 131$ parameter from 700 to $800{ }^{\circ} \mathrm{C}$ is approximately $0.02^{\circ}(2 \theta)$. In the present study, the $\Delta 131$ parameters of each crystal can be determined with an error of less than $0.01^{\circ}(2 \theta)$; consequently, temperatures in the range $700-800^{\circ} \mathrm{C}$ can be determined with an error of less than $50^{\circ} \mathrm{C}$. Smith (1972) did not draw the line indicating temperatures less than $700{ }^{\circ} \mathrm{C}$ in his relation diagram because the time required to attain equilibrium in synthetic plagioclase is much longer than that for $\mathrm{Na}$-rich plagioclases, especially at lower temperatures. Consequently, the crystallization temperatures of the crystals analyzed in the present study that plot below the $700{ }^{\circ} \mathrm{C}$ line in Figure 5 cannot be determined. However, it is clear that three of the six analyzed crystals (Crystals 1,2 and 3) 
Table 2. Chemical and X-ray data for plagioclase crystals from the Kobe meteorite

\begin{tabular}{ccccccc}
\hline $\begin{array}{c}\text { Plagioclase } \\
\text { Crystal }\end{array}$ & An & $\begin{array}{c}\mathrm{Ab} \\
(\mathrm{mol} \%)\end{array}$ & Or & \multicolumn{3}{c}{$\Delta 131 \mathrm{Cu} \mathrm{K \alpha}$ (degree) } \\
\hline 1 & 54.7 & 43.3 & 2.0 & 1.938 & 0.030 & 1.968 \\
2 & 63.3 & 35.1 & 1.6 & 1.996 & 0.018 & 2.014 \\
3 & 59.8 & 38.3 & 1.9 & 1.975 & 0.025 & 2.000 \\
4 & 57.2 & 41.2 & 1.6 & 1.937 & 0.021 & 1.958 \\
5 & 60.7 & 37.7 & 1.6 & 1.911 & 0.020 & 1.931 \\
6 & 63.1 & 35.5 & 1.4 & 1.946 & 0.017 & 1.963 \\
\hline
\end{tabular}

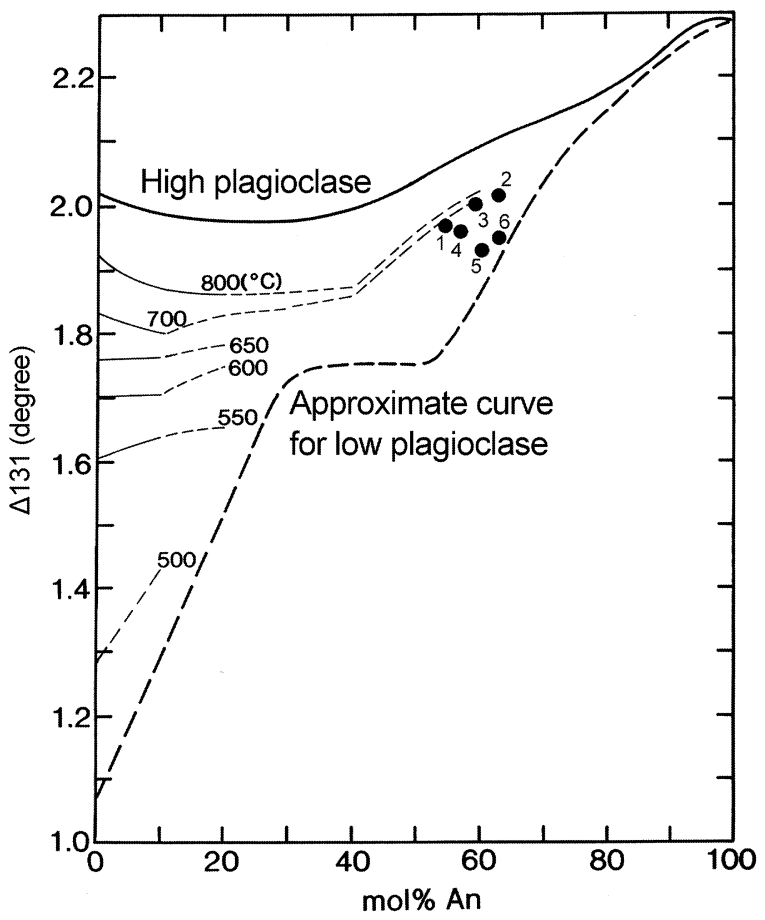

Figure 5. Plot of plagioclase crystals on the relation diagram between the $\Delta 131$ parameter and the temperature of plagioclase synthesis proposed by Smith (1972).

show similar temperatures, of slightly less than $700{ }^{\circ} \mathrm{C}$, which are on the high side of plagioclase temperatures determined in this study, although the three crystals of similar temperature have contrasting chemical compositions.

\section{DISCUSSION}

Temperatures indicated by plagioclase and comparison with other thermometers

Plagioclases from the Kobe meteorite show sharp X-ray reflections that indicate well crystallinity. The structural states of these feldspars reveal that three of the investigated crystals record similar temperatures of slightly less than $700{ }^{\circ} \mathrm{C}$ and the others record much lower temperatures.

Based on the geologically common occurrence of zoned plagioclase crystals and heating experiments, Goldsmith $(1952,1987)$ suggested that order-disorder reactions in plagioclase are extremely sluggish in a dry environment; this has also been suggested for chondrites (Dodd, 1981). The slow progress of the reactions has been discussed in detail in terms of the bond strength between $\mathrm{Si}$ or Al and oxygen (Goldsmith, 1952, 1987). As ordering reactions in plagioclase are very slow (Goldsmith, 1952; Van Schmus and Ribbe, 1968; Goldsmith, 1987), the structural state of plagioclase observed in the present study is considered to closely resemble the state when plagioclase crystallized and therefore to reflect the crystallization temperature of the plagioclase (Nakamuta and Motomura, 1999).

The solidus temperature of plagioclase with the composition $\mathrm{An}_{55-65}$, as analyzed in the present study, is approximately $1300^{\circ} \mathrm{C}$ (Bowen, 1913). Compared with this temperature, the temperatures of plagioclases obtained in this study are too low for the plagioclase to be interpreted as resulting from crystallization direct from a melt or crystallization during cooling from the solidus temperature. Nakamuta et al. (2005) reported the structural states of plagioclase from the Caddo County IAB iron meteorite and found that plagioclase that formed at comparatively low temperatures shows albite twins under an optical microscope. The albite twins are thought to have formed during a cooling process via the ordering of $\mathrm{Al}$ and $\mathrm{Si}$ in the tetrahedral sites. The twins are considered to be characteristic of plagioclase that forms via a cooling process. As such twins are absent in the Kobe meteorite, it is reasonable to consider that plagioclase in the Kobe meteorite crystallized via a heating process, i.e., during thermal metamorphism. The highest temperature indicated by the 
plagioclase crystals analyzed in the present study may therefore correspond to the peak temperature of the thermal metamorphism, being close to but not exceeding $700{ }^{\circ} \mathrm{C}$.

Clayton et al. (1977) reported 590 and $580{ }^{\circ} \mathrm{C}$ concordant isotopic temperatures for the Karoonda CK4 chondrite on the basis of plagioclase-magnetite pairs and plagioclase-olivine pairs, respectively. Geiger and Bischoff (1991) reported temperatures for the paragenesis of low-Ca and high-Ca pyroxenes of $680{ }^{\circ} \mathrm{C}$ for EET 87507 (CK5) and $720^{\circ} \mathrm{C}$ for Maralinga (CK4), respectively. Based on determined equilibration temperatures of coexisting pyroxenes and the metamorphic temperature of the Karoonda meteorite, Clayton et al. (1977) estimated metamorphic temperatures of $550-650{ }^{\circ} \mathrm{C}$ for type $4 \mathrm{CK}$ chondrites, $650-800{ }^{\circ} \mathrm{C}$ for type 5 , and $800-1000{ }^{\circ} \mathrm{C}$ for type 6. Based on the olivine-spinel geothermometer, Noguchi (1993) suggested that Maralinga (CK4), Y-693 (CK4), EET 787507 (CK5), and some fragments in Karoonda (CK4) were heated to at least $750-850^{\circ} \mathrm{C}$, which is higher than the temperature estimated by Geiger and Bischoff (1991). Tachibana et al. (2002) also reported higher temperatures for the Kobe meteorite of 800 and $880^{\circ} \mathrm{C}$ based on the chemical composition of high-Ca pyroxene and the olivine-spinel geothermometer, respectively. The temperatures estimated in the present study may therefore be comparable with the type 4 temperatures estimated by Geiger and Bischoff (1991).

The pyroxene thermometer and olivine-spinel thermometer are based on the distribution of cations among related minerals, and the obtained temperature is largely assessed in terms of the diffusion rates of cations. When these thermometers are applied to chondrite meteorites, it may be problematic that the diffusion rates of cations are too slow to attain equilibrium between related minerals. McSween and Patchen (1989) and Jones (1997) suggested that two pyroxenes even in type 6 ordinary chondrites failed to attain equilibration. In contrast to these thermometers, the plagioclase thermometer is based on the distribution of $\mathrm{Si}$ and $\mathrm{Al}$ in the unit cell of plagioclase, which contributes to the entropy term of free energy and is therefore related to temperature. This thermometer does not rely in principle on the composition of plagioclase. Tachibana et al. (2002) failed to find an augite-orthopyroxene pair in their PTS from the Kobe meteorite because all orthopyroxene grains were surrounded by irregularly shaped pentlandite. Their assumption that augite and orthopyroxene had equilibrated was based solely only on the homogeneous compositions of both pyroxenes. However, homogeneous pyroxene compositions in a meteorite do not necessarily indicate equilibration between augite and orthopyroxene during thermal metamorphism; in- stead, they may indicate that CK chondrites have experienced a much more complex thermal history compared with that of ordinary chondrites. This topic will be discussed further in the following section.

\section{Origin of plagioclase and the thermal history of the CK parent body}

The dominant constituent minerals in CK chondrites, olivine and pyroxene, are homogeneous in chemical composition, as are those in metamorphosed ordinary chondrites. However, plagioclase in CK chondrites is compositionally variable $\left(\mathrm{An}_{23-90}\right)$, whereas plagioclase in ordinary chondrites shows more homogeneous compositions $\left(\mathrm{An}_{9-20}\right)$. For ordinary chondrites, plagioclase is thought to have crystallized during thermal metamorphism from preexisting $\mathrm{Na}$-rich glass, which may be a quenched residual melt following differentiation within chondrules or within nebula dust (Van Schmus and Wood, 1967; Nakamuta and Motomura, 1999). The grain sizes of plagioclase in ordinary chondrites increase with increasing petrographic type and are used as an index of the metamorphic grade of ordinary chondrites (Van Schmus and Wood, 1967; Heyse, 1978).

Kallemeyn et al. (1991), Rubin (1992), and Tomeoka et al. (2005) suggested that the heterogeneity of plagioclase in CK chondrites may reflect fractionation during shock melting or crystallization following shock melting. Noguchi (1993) argued that compositionally homogeneous feldspars in ordinary chondrites resulted from crystallization in veins and melt pockets of various compositions, involving crystallization of plagioclase (calcic to sodic) followed by cotectic crystallization of sodic plagioclase and $\mathrm{K}$-feldspar. However, Noguchi failed to find feldspar crystals in CK chondrites that were consistent with such a compositional trend. In CK chondrites, Noguchi found reverse zoning of matrix plagioclase, regardless of the degree of recrystallization, and suggested that rims of matrix plagioclase formed by thermal metamorphism whereas cores may be primarily condensates from the nebula that recrystallized during thermal metamorphism. Ivanova et al. (2000) found that the Dhofar 015 meteorite shows several properties indicative of a lack of intensive thermal metamorphism, consistent with type 3. Plagioclase in the Dhofar 015 chondrite ranges from $\mathrm{An}_{16-99}$, and occurs as plagioclase-rich inclusions together with primary glass in chondrules. Such an occurrence of plagioclase suggests that the variable chemical compositions of plagioclase found in metamorphosed CK chondrites may also have originated in the nebula. The fact that the grain sizes of plagioclase are inconsistent with the sizes expected from the petrographic type estimated from 
matrix grain sizes (Tomeoka et al., 2005) may partly reflect an origin in the nebula, as suggested by Noguchi (1993) and Ivanova et al. (2000).

Rubin (1992) suggested that the darkening of CK chondrites resulted from the intrusion of opaque minerals into silicate minerals during shock, although many CK chondrites exhibit light shock effects in olivine that are consistent with equilibrium shock pressures that are too low to account for the observed silicate darkening. Rubin interpreted the light shock effects in olivine as a product of annealing during thermal metamorphism subsequent to the intense shock that caused the original darkening. However, Scott et al. (1992) pointed out that the annealing of shock features generated at the shock level at which silicate darkening occurs requires a degree of thermal metamorphism that is characteristic of petrographic type 6, and many of the $\mathrm{CK}$ chondrites that contain darkened silicates show the characteristics of petrographic type 4, as with the Kobe meteorite. Tomeoka et al. (2001, 2005) suggested that inclusion-rich vesicular olivine is the principal cause of silicate darkening and that vesicular olivine was generated by shock metamorphism at a relatively mild shock pressure $(<25 \mathrm{GPa})$ and high temperatures $\left(>600{ }^{\circ} \mathrm{C}\right)$, probably at the state where the meteorite underwent thermal metamorphism.

The sharp X-ray reflections of plagioclase crystals analyzed in the present study indicate that they have not suffered a heavy shock event following the crystallization that occurred during thermal metamorphism, as discussed above. This suggests that the shock event that caused silicate darkening may have occurred prior to the thermal metamorphism in which plagioclase crystallized. This interpretation appears to agree with that of Rubin (1992), who suggested that silicate darkening occurred prior to thermal metamorphism. However, as noted by Scott et al. (1992), the light shock effects in olivine cannot be explained by his interpretation. It is therefore reasonable to consider that silicate darkening occurred at a relatively mild shock pressure and a high temperature, as suggested by Tomeoka et al. (2001). The interpretation of silicate darkening proposed by Tomeoka et al. (2001) and the results of the present study lead to the following thermal history of the CK parent body: the CK chondrites were heated to a high temperature prior to the occurrence of shock events that caused silicate darkening, then cooled to below the temperature at which plagioclase glass formed before being heated again to the metamorphic temperature determined in the present study. Such an apparently complex thermal history can be interpreted in a simple way by assuming that thermal metamorphism began prior to accretion of the CK parent body, with the decay of ${ }^{26} \mathrm{Al}$ as a heat source.
The decay of ${ }^{26} \mathrm{Al}$ is thought to be a likely candidate for the heat source of thermal metamorphism of a chondrite parent body, and model calculations using an ${ }^{26} \mathrm{Al}$ heat source have been undertaken previously by Miyamoto et al. (1981), Miyamoto (1991), and Bennett and McSween (1996). In these earlier calculations, Miyamoto (1991) showed that the temperature reaches about $550{ }^{\circ} \mathrm{C}$ in the center of a body with a $10 \mathrm{~km}$ radius, a $\mathrm{CM}$ chondrite bulk composition, and a $5 \times 10^{-6}{ }^{26} \mathrm{Al} /{ }^{27} \mathrm{Al}$ ratio that corresponds to $2.5 \mathrm{Ma}$ after the Allende CAI formation. As CK chondrites are richer in Al than CM chondrites (Kallemeyn et al., 1991), a body with a CK chondrite composition and $10 \mathrm{~km}$ radius may record much higher temperatures in its center than $550{ }^{\circ} \mathrm{C}$. A smaller body with a radius of less than $10 \mathrm{~km}$ may also have experienced high temperatures if it formed earlier than 2.5 Ma after CAI formation. We have only a poor understanding of the thermal history of materials prior to the accretion to a chondrite parent body; however, calculation results raise the possibility that planetesimals accreting to the CK parent body may have been at a high temperature at which a relatively mild shock event can cause the silicate darkening of CK chondrites (Tomeoka et al., 2001). Plagioclase that originated in the nebula may have melted due to its susceptibility to a shock event of the type that causes the darkening of olivine (Rubin, 1992; Tomeoka et al., 2001). Following shock events that accompany the accretion of the CK parent body, heat accumulated in small bodies prior to accretion may have been partly or completely lost during the fragmentation of the bodies. The materials accreting to form the CK parent body may therefore have cooled to a temperature at which plagioclase glass would have formed. Following accretion of the CK parent body, heat produced by the decay of ${ }^{26} \mathrm{Al}$ may have accumulated within the parent body, leading to thermal metamorphism as in the case of ordinary chondrites (Nakamuta and Motomura, 1999).

The thermal model proposed above provides for a simple interpretation of the homogeneous compositions of olivine and pyroxene in $\mathrm{CK}$ chondrites, which are inconsistent with the petrographic type suggested by matrix grain sizes (Tachibana et al., 2002; Tomeoka et al., 2005), as well as the occurrence of silicate darkening in almost all CK chondrites (Kallemeyn et al., 1991). The model suggests that the exchange of cations in olivine and pyroxene may have begun in small bodies prior to accretion and proceeded rapidly at high temperatures attained by shock, although grain growth of the matrix minerals may have been too slow for the minerals to grow in small bodies prior to accretion. 


\section{ACKNOWLEDGMENTS}

We thank Mr. R. Hirata for providing samples of the Kobe meteorite. We also thank Drs. Y. Ikeda, T. Noguchi, and K. Tomeoka for helpful reviews of the manuscript. This work was supported by a Grant-in-Aid (No. 16540440) and "The 21st Century COE Program of the Origin and Evolution of Planetary Systems" of the Japan Ministry of Education, Culture, Sports, Science and Technology.

\section{REFERENCES}

Bambauer, H.U., Eberhard, E. and Viswanathan, K. (1967) The lattice constants and related parameters of "plagioclases (low)". Schweizer Mineralogie unt Petrographie Mittenshaft, 47, 351-364.

Bennett, M.E., III and McSween, H.Y., Jr. (1996) Revised model calculations for the thermal histories of ordinary chondrite parent bodies. Meteoritics \& Planetary Science, 31, 783-792.

Bowen, N.L. (1913) The melting phenomena of the plagioclase feldspars. American Journal of Science, 35, 577-599.

Clayton, R.N., Onuma, N., Grossman, L. and Mayeda, T.K. (1977) Distribution of the pre-solar component in Allende and other carbonaceous chondrites. Earth and Planetary Science Letters, 34, 209-224.

Dodd, R.T. (1981) Meteorites: A Petrologic-Chemical Synthesis. Cambridge University Press, New York, 90-97.

Eberhard, E. (1967) Zur Synthese der Plagioklase. Schweizer Mineralogie unt Petrographie Mittenshaft, 47, 385-398.

Gandolfi, G. (1967) Discussion upon methods to obtain X-ray 《powder patterns》from a single crystal. Mineralogica et Petrographica Acta, 13, 67-74.

Geiger, T. and Bischoff, A. (1991) The CK chondrites-Conditions of parent body metamorphism (abstract). Meteoritics, 26, 337.

Geiger, T. and Bischoff, A. (1995) Formation of opaque minerals in CK chondrites. Planetary and Space Science, 43, 485-498.

Goldsmith, J.R. (1952) Diffusion in plagioclase feldspars. Journal of Geology, 60, 288-291.

Goldsmith, J.R. (1987) Al/Si interdiffusion in albite: effect of pressure and the role of hydrogen. Contribution to Mineralogy and Petrology, 95, 311-321.

Heyse, J.V. (1978) The metamorphic history of LL-group ordinary chondrites. Earth and Planetary Science Letter, 40, 365 381.

Ivanova, M.A., Nazarov, M.A., Kononkova, N.N., Taylor, L.A., Patchen, A., Clayton, R.N. and Mayeda, T.K. (2000) Dhofar 015, a new CK3 chondrite: A record of nebular processes (abstract). Meteoritics \& Planetary Science, 35 (Supplement), A83.

Jones, R.H. (1997) Equilibration of pyroxenes in type 4-6 LL chondrites (abstract). Lunar and Planetary Science, 28, 681682, Lunar and Planetary Institute, Houston, Texas, USA.

Kallemeyn, G.W., Rubin, A.E. and Wasson, J.T. (1991) The compositional classification of chondrites: V. The Karoonda (CK) group of carbonaceous chondrites. Geochimica et Cosmochimica Acta, 55, 881-892.

Kiriyama, K., Tomeoka, K. and Sekine, T. (2000) Experimental shock metamorphism of the Allende $\mathrm{CV}$ chondrite at pressures from 20 to $50 \mathrm{GPa}$ (abstract). Meteoritics \& Planetary
Science, 35 (Supplement), A88.

Kroll, H. and Ribbe, P. H. (1980) Determinative diagrams for Al, $\mathrm{Si}$ order in plagioclases. American Mineralogist, 65, 449457.

MacKenzie, W.S. (1957) The crystalline modifications of $\mathrm{NaAlSi}_{3} \mathrm{O}_{8}$. American Journal of Science, 255, 481-516.

McSween, H.Y., Jr. and Patchen, A.D. (1989) Pyroxene thermometry in LL-group chondrites and implications for parent body metamorphism. Meteoritics, 24, 219-226.

McSween, H.Y., Jr., Sears, D.W.G. and Dodd, R.T. (1988) Thermal metamorphism. In Meteorites and the Early Solar System (Kerridge, J.R. and Matthews, J.R.). University Arizona Press, Tucson, Arizona, 102-113.

Miyamoto, M. (1991) Thermal metamorphism of CI and CM carbonaceous chondrites: An internal heating model. Meteoritics, 26, 111-115.

Miyamoto, M., Fujii, N. and Takeda, H. (1981) Ordinary chondrite parent body: An internal heating model. Proceedings of Lunar and Planetary Science, 12B, 1145-1152.

Nakamura, N. (2002) Special issue: The Kobe meteorite consortium preface. Geochemical Journal, 36, 289-293.

Nakamura, N., Ebihara, M., Hirota, Y., Oura, Y., Yoneda, K., Kojima, H., Tomeoka, K. Kojima, T., Komura, K., Clayton, R.N., Mayeda, T.K. and Wang, D. (2000) The Kobe meteorite: Preliminary results of bulk chemical composition, petrography, cosmic-ray induced radioactivities, oxygen isotopes and classification (abstract). Lunar and Planetary Science, 31, \#1234, Lunar and Planetary Institute, Houston, Texas, USA (CD-ROM).

Nakamura, T., Tomeoka, K., Takaoka, N., Sekine, T. and Takeda, H. (2000) Impact-induced textural changes of CV carbonaceous chondrite: Shock experiments. Meteoritics, 30, 344-347.

Nakamuta, Y. (1993) The determination of lattice parameters of a small crystal with a Gandolfi camera. Journal of Mineralogical Society of Japan, 22, 113-122 (Japanese with English abstract)

Nakamuta, Y. (1999) Precise analysis of a very small mineral by an $\mathrm{X}$-ray diffraction method. Journal of Mineralogical Society of Japan, 28, 117-121 (Japanese with English abstract).

Nakamuta, Y. and Motomura, Y. (1999) Sodic plagioclase thermometry of type 6 ordinary chondrites: Implications for the thermal histories of parent bodies. Meteoritics and Planetary Science, 34, 763-772.

Nakamuta, Y., Owaki, R. and Takeda, H. (2005) Plagioclase thermometry of Caddo County IAB iron meteorite (abstract). $29^{\text {th }}$ Symposium on Antarctic Meteorites, National Institute of Polar Research, Tokyo, Japan, 51-52.

Noguchi, T. (1993) Petrology and mineralogy of CK chondrites: Implications for the metamorphism of the CK chondrite parent body. Proceedings of National Institute of Polar Research Symposium on Antarctic Meteorites, National Institute of Polar Research, Tokyo, Japan, 6, 204-233.

Rubin, A. (1992) A shock-metamorphic model for silica darkening and compositionally variable plagioclase in CK and ordinary chondrites. Geochimica et Cosmochimica Acta, 56, 1705-1714.

Scott, E.R.D., Keil, K. and Stöffler, D. (1992) Shock metamorphism of carbonaceous chondrites. Geochimica et Cosmochimica Acta, 56, 4281-4293.

Smith, J.R. and Yoder, H.S. (1956) Variations in X-ray powder diffraction patterns of plagioclase feldspars. American Mineralogist, 41, 632-647. 
Smith, J.V. (1972) Critical review of synthesis and occurrence of plagioclase feldspars and a possible phase diagram. Journal of Geology, 80, 505-525.

Stöffler, D., Keil, K., and Scott, E.R.D. (1991) Shock metamorphism of ordinary chondrites. Geochimica et Cosmochimica Acta, 55, 3845-3867.

Tachibana, Y., Kitamura, M., Hirajima, T. and Nakamura, N. (2002) Equilibration temperature of the Kobe meteorite. Geochemical Journal, 36, 323-332.

Tomeoka, K., Yamahana, Y. and Sekine, T. (1999) Experimental shock metamorphism of the Murchison CM carbonaceous chondrite. Geochimica et Cosmochimica Acta, 63, 36833703.

Tomeoka, K., Ohnishi, I. and Nakamura, N. (2001) Silicate darkening in the Kobe CK chondrite: Evidence for shock metamorphism at high temperature. Meteoritics \& Planetary Science, 36, 1535-1545.
Tomeoka, K., Kojima, T., Ohnishi, I., Ishii, Y. and Nakamura, N. (2005) The Kobe CK carbonaceous chondrite: petrography, mineralogy and metamorphism. Journal of Mineralogical and Petrological Sciences, 100, 116-125.

Tuttle, O.F. and Bowen, N.L. (1950) High-temperature albite and contiguous feldspars. Journal of Geology, 58, 572-583.

Van Schmus, W.R. and Ribbe, P.H. (1968) The composition and structural state of feldspar from chondritic meteorites. Geochimica et Cosmochimica Acta, 32, 1327-1342.

Van Schmus, W.R. and Wood, J.A. (1967) A chemical-petrologic classification for the chondritic meteorites. Geochimica et Cosmochimica Acta, 31, 747-765.

Manuscript received January 6, 2006

Manuscript accepted June 14, 2006

Published online November 24, 2006

Manuscript handled by Kazushige Tomeoka 